\title{
Facilitating the indirect detection of genomic DNA in an electrochemical DNA biosensor using magnetic nanoparticles and DNA ligase
}

\begin{abstract}
An integrated treatment system which incorporated an anaerobic-aerobic-wetland sequential system (AAWSS) and a convective sludge dryer (CSD) was established to treat highly polluting palm oil mill effluent (POME) in a shorter retention period and with a smaller area requirement. Before actual treatment, a start-up operation was performed to achieve optimal degradation performance. The strategy involved a stepwise feeding from 0.2 to $1 \mathrm{~m} 3 \mathrm{~d}-1$ at three day intervals for 15 days. During the operation, the lowest hydraulic retention time of 21 days was achieved and the biogas production was gradually increased from 1442 to $11,028 \mathrm{~kg} \mathrm{~d}-1$ with the increase of organic loads from 0.46 to $2.2 \mathrm{~kg} \mathrm{~m}-3 \mathrm{~d}-1$. COD, VSS and VFA were almost completely (99\%) removed, whereas the average percentage removals of SS and TN were $96 \%$ and $72 \%$, respectively. To demonstrate the plant's robustness in treating POME, the AAWSS was proceeded with a 360 days operation. A slight deterioration in COD and SS removals were observed from day 225 to day 265 due to an organic shock load. One unanticipated finding was that the AAWSS regained its stability shortly thereafter thus ensuring consistency of the treatment performance for long-term use. Further treatment with CSD was designed to produce a clear effluent that surpassed the industrial effluent discharge limits at low-cost. By referring to mass balance, the production efficiency achieved $95 \%$ condensate yield, leaving $7 \%$ concentrate and $2 \%$ dewatered solids as byproducts.
\end{abstract}

Keyword: POME; Integrated wastewater system; Wetland; Convective drying system; Anaerobic-aerobic treatment 